Article

\title{
Numerical Analysis on the Cooling Performance of a Hybrid Personal Cooling System (HPCS) under Different Hot Environments
}

\author{
Zhanxiao Kang ${ }^{1}$, Xianfu Wan ${ }^{2}$, Faming Wang ${ }^{1,}$, , Udayraj ${ }^{1}$, Bin Yang ${ }^{3}$ \\ 1 Thermal Environment and Ergonomics Group (TEEG), Institute of Textiles \& Clothing, The Hong Kong \\ Polytechnic University, Hung Hom, Kowloon, Hong Kong \\ 2 Key Laboratory of Textile Science \& Technology (Donghua University), Ministry of Education, Shanghai, \\ China \\ 3 School of Environmental and Municipal Engineering, Xi'an University of Architecture and Technology, \\ Xi'an, China \\ * Correspondence: dr.famingwang@gmail.com; faming.wang@polyu.edu.hk; Tel.: +(852) 2766-6489
}

\begin{abstract}
The hybrid personal cooling system (HPCS) consisted of ventilation fans and phase change materials (PCMs) covered with insulation pads is a promising wearable cooling system to mitigate heat strain and heat-related illnesses of occupational workers with heavy labor in hot environments. Effects of clothing characteristics (e.g., thermal resistance of insulation pads, latent heat and melting temperature of PCMs) on the thermal performance of the HPCS have been investigated in detail in our previous study. Apart from the aforementioned factors, environmental conditions, i.e., environmental temperature and relative humidity, also significantly affect the thermal performance of the HPCS. In this paper, a numerical parametric study was performed to investigate the effects of the environmental temperature and relative humidity $(\mathrm{RH})$ on the thermal management of the HPCS. Five levels of air temperature under environmental $\mathrm{RH}=50 \%$ were chosen (i.e., $32,34,36,38$ and $40^{\circ} \mathrm{C}$ ) to study the impact of environmental temperature on the HPCS's cooling performance. In addition, four levels of environmental $\mathrm{RH}$ at ambient temperatures of 36 and $40^{\circ} \mathrm{C}$ were selected (i.e., 30, 50, 70 and $90 \%$ ) to examine the effect of $\mathrm{RH}$ on cooling performance of the HPCS. Results show that high environmental temperatures could accelerate the PCM melting process and thereby weaken the cooling performance of HPCS. In the moderately hot environment $\left(36{ }^{\circ} \mathrm{C}\right)$, the HPCS presented good cooling performance with the maximum core temperature at around $37.5{ }^{\circ} \mathrm{C}$ during excise when the ambient $\mathrm{RH} \leq 70 \%$, whereas good cooling performance could be only seen under $\mathrm{RH} \leq 50 \%$ in the extremely hot environment $\left(40{ }^{\circ} \mathrm{C}\right)$. Thus, it may be concluded that the maximum environmental RH for the HPCS exhibiting good cooling performance decreases with the increase in the environmental temperature.
\end{abstract}

Keywords: personal cooling system; heat and mass transfer; environmental temperature; relative humidity; phase change materials; thermal management

\section{Introduction}

Heat waves are becoming a significant threat to the society and the human health due to global climate change in recent years [1,2]. During heat wave periods or in hot environments, outdoor workers (e.g., in agricultural, industrial or construction sectors) may suffer from rigorous heat strain which could lead to severe heat-related illnesses and injuries, including heat rashes, heat cramps, heat exhaustion, heat stroke, and even mortality [3-6]. To attenuate the heat strain of such occupational workers with heavy labor in hot environments, portable personal cooling systems (PCSs) have been proposed and developed [7-14], including fluid cooling, phase change materials (PCMs) cooling, evaporative cooling, thermoelectric cooling, vacuum desiccant cooling, and radiative cooling. Nevertheless, each single cooling approach has limitations [15-18]. For example, the ventilation air 
fanned from environment might transport ambient heat to the human body if the environmental temperature were greater than the skin temperature; the PCMs generally hinder the moisture dissipation from the skin to the ambient environment; the evaporative cooling does not work well in the hot environments with a high relative humidity. Therefore, hybrid cooling systems incorporated with two or more cooling methods in one cooling system were proposed and investigated [19-22] so as to overcome the limitations brought by the single cooling technique. Webbon et al. [19] found garments incorporated with the liquid and ventilation cooling could provide better thermal comfort for the astronauts as compared to single cooling systems. Wang et al. [20] studied the performance of a liquid cooling garment incorporated with PCM microcapsules, which showed that the inlet temperature, mass flow rate and the volume concentration of PCM microcapsules must be adjusted appropriately to achieve the best cooling performance. Song and Wang [21] integrated PCM packs and ventilation fans into one cooling garment named as hybrid personal cooling system (HPCS), and found that the HPCS could significantly reduce the heat strain of wearers in hot environments.

Among existing hybrid personal cooling systems, the combination of PCM packs and ventilation fans has been widely chosen [21-24]. For HPCSs incorporated with PCMs and ventilation fans, the PCM packs are generally discretely positioned at different body sites. Such a design pattern permits the skin moisture evaporation through the gaps between adjacent PCM packs. Meanwhile, the moisture can also be transported away to the ambient environment by the forced ventilation air. Hence, the relative humidity in the HPCS systems could be reduced significantly and thereby this greatly improves the wetness sensation while wearing the HPCS. In addition, after the PCMs are completely melted, the human body still could be cooled by the ventilation air through convective or/and evaporative heat transfer. Furthermore, even when the ventilation temperature is higher than the skin temperature, the PCM packs could also cool the human body via radiative heat transfer and thereby attenuate the heat stress. Nevertheless, Wan et al.'s study [25] has shown that a prominent portion of the PCM cooling energy was wasted to the ambient since the PCM packs absorbed much heat from the hot environment. Consequently, the PCM melting process could be accelerated leading to a shorter efficient body cooling duration brought by PCMs.

In order to solve the early melting issue of the PCMs in the HPCS, the HPCS was redesigned by adding additional EPE (expanded polyethylene) insulation in between the PCM packs and the outer clothing layer (hereby denoted as the new HPCS), and its cooling performance influenced by the clothing characteristics was examined by a recent numerical study [26]. The results showed that the new HPCS could significantly reduce the heat drawn by the PCMs from the hot environment at $36{ }^{\circ} \mathrm{C}$ and $\mathrm{RH}=59 \%$. Furthermore, the EPE pads with large insulation level and PCMs with high latent heat \& high melting temperature could contribute to the thermal management of the new HPCS. Nevertheless, apart from the aforementioned clothing factors, environmental conditions such as temperature and relative humidity $(\mathrm{RH})$, are also reported to play a significant role in affecting the cooling performance of PCSs[18, 27-29]. It is anticipated that high environmental temperatures could enhance the melting process of the PCMs and thereby shorten the effective cooling duration of the HPCS. Also, high environmental RHs could suppress the sweat evaporation from the skin surface and thus weaken the evaporative heat dissipation from the human body. Moreover, the moisture in the ambient environment might be condensed on the PCM surface at sufficiently high environmental RHs, which also shortens the PCM melting process and hence reduces the efficient working time of the HPCS. Hence, the results reported in our previous study[26] cannot be generalized to any environmental condition other than the studied condition (i.e., $36^{\circ} \mathrm{C}, \mathrm{RH}=59 \%$ ). Therefore, it's very meaningful to examine the effects of the environmental temperature and $\mathrm{RH}$ on the cooling performance of the new HPCS so as to guide the energy-efficient application of the HPCS in various environmental conditions.

In this paper, based on the validated numerical model shown in our previous study[26], we performed a numerical parametric study to investigate the effects of the environmental temperature and relative humidity $(\mathrm{RH})$ on the cooling performance of the new HPCS. The human physiological responses (e.g., mean skin temperature, chest temperature \& core temperature) and such parameters used to characterize the PCM thermal performance (e.g., PCM temperature and PCM heat 
absorptions form environment \& body) under different environmental conditions were examined and compared. In the parametric study, five levels of environmental temperature under ambient $\mathrm{RH}=50 \%$ were chosen (i.e., $32,34,36,38$ and $40{ }^{\circ} \mathrm{C}$ ) to investigate the effect of air temperature on the HPCS's cooling performance. Meanwhile, four levels of environmental $\mathrm{RH}$ at 36 and $40{ }^{\circ} \mathrm{C}$ were selected (i.e., 30, 50, 70 and 90\%) to examine the influence of RH on the cooling performance of the HPCS. This study is of great importance for optimizing the application of the HPCS in a specific hot and humid environment, which is beneficial to reduce heat stress and heat-related illnesses for outdoor workers in hot environments by an energy-efficient way.

\section{Methodology}

\subsection{Description of the HPCS}

The new HPCS was composed of a long-sleeve jacket and a pair of full-length trousers as indicated in Figure 1. Twenty-four PCM packs with insulation pads were housed in the clothing inner pockets. More specifically, six, eight, four and six PCM packs were located at the chest, upper back, upper arms and thighs, respectively. The insulation pads were positioned in between the PCM packs and the outer clothing layer. In addition, four ventilation fans with a diameter of $9.8 \mathrm{~cm}$ were installed at the lower back and near pelvis region of the HPCS so as to minimize the body movement restriction.

The material of the underwear and the pocket layer was 100\% polyester with the thicknesses of $0.356 \mathrm{~mm}$ and $0.160 \mathrm{~mm}$, respectively. The specific heat capacity and the moisture regain of the

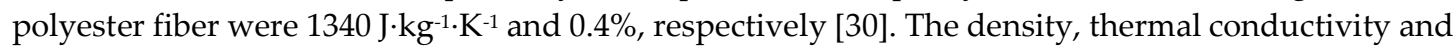
water vapor resistance of the underwear were $317 \mathrm{~kg} \cdot \mathrm{m}^{-3}, 0.0614 \mathrm{~W} \cdot \mathrm{m}^{-1} \cdot \mathrm{K}^{-1}$ and $1.49 \mathrm{~m} \cdot \mathrm{Pa} \cdot \mathrm{W}-1$, respectively, whereas the corresponding parameters of the pocket layer were $392 \mathrm{~kg} \cdot \mathrm{m}^{-3}, 0.0371 \mathrm{~W} \cdot \mathrm{m}$ ${ }^{1} \cdot \mathrm{K}^{-1}$ and $0.56 \mathrm{~m}^{2} \cdot \mathrm{Pa} \cdot \mathrm{W}^{-1}$, respectively. The component of the clothing outer layer was $100 \%$ cotton with a thickness of $0.338 \mathrm{~mm}$. The specific heat capacity and moisture regain of the cotton fiber were $1210 \mathrm{~J} \cdot \mathrm{kg}^{-1} \cdot \mathrm{K}^{-1}$ and $8.5 \%$, respectively [30]. The density, thermal conductivity and water vapor resistance of the outer clothing layer were $607 \mathrm{~kg} \cdot \mathrm{m}^{-3}, 0.0592 \mathrm{~W} \cdot \mathrm{m}^{-1} \cdot \mathrm{K}^{-1}$ and $4.0 \mathrm{~m}^{2} \cdot \mathrm{Pa} \cdot \mathrm{W}^{-1}$, respectively.

The ingredient of the PCM packs was the sodium sulfate decahydrate $\left(\mathrm{Na}_{2} \mathrm{SO}_{4} \cdot 10 \mathrm{H}_{2} \mathrm{O}\right)$ with the latent heat and the melting temperature of $144 \mathrm{~kJ} / \mathrm{kg}$ and $21^{\circ} \mathrm{C}$, respectively. The density, specific heat capacity and the thermal conductivity of the PCMs were $500 \mathrm{~kg} \cdot \mathrm{m}^{-3}, 3600 \mathrm{~J} \cdot \mathrm{kg}^{-1} \cdot \mathrm{K}^{-1}$ and $0.6 \mathrm{~W} \cdot \mathrm{m}-$ ${ }^{1} \cdot \mathrm{K}^{-1}$, respectively [31]. The length and width of the PCM packs were $120 \mathrm{~mm}$ and $70 \mathrm{~mm}$, respectively, and the total weight of the 24 PCM packs was $1.54 \mathrm{~kg}$. In addition, the material of the insulation pads was expanded polyethylene (EPE) and the thickness of each insulation pad was $5 \mathrm{~mm}$ with the corresponding thermal resistance of $0.167 \mathrm{~m}^{2} \cdot \mathrm{K} \cdot \mathrm{W}^{-1}$. The density, specific heat capacity and the thermal conductivity of the insulation pads were $20 \mathrm{~kg} \cdot \mathrm{m}^{-3}, 1340 \mathrm{~J} \cdot \mathrm{kg}^{-1} \cdot \mathrm{K}^{-1}$ and $0.03 \mathrm{~W} \cdot \mathrm{m}^{-1} \cdot \mathrm{K}^{-1}$, respectively. The length and width of each insulation pad were the same as those of the PCM packs and the total weight of the 24 insulation pads was $22.0 \mathrm{~g}$. 


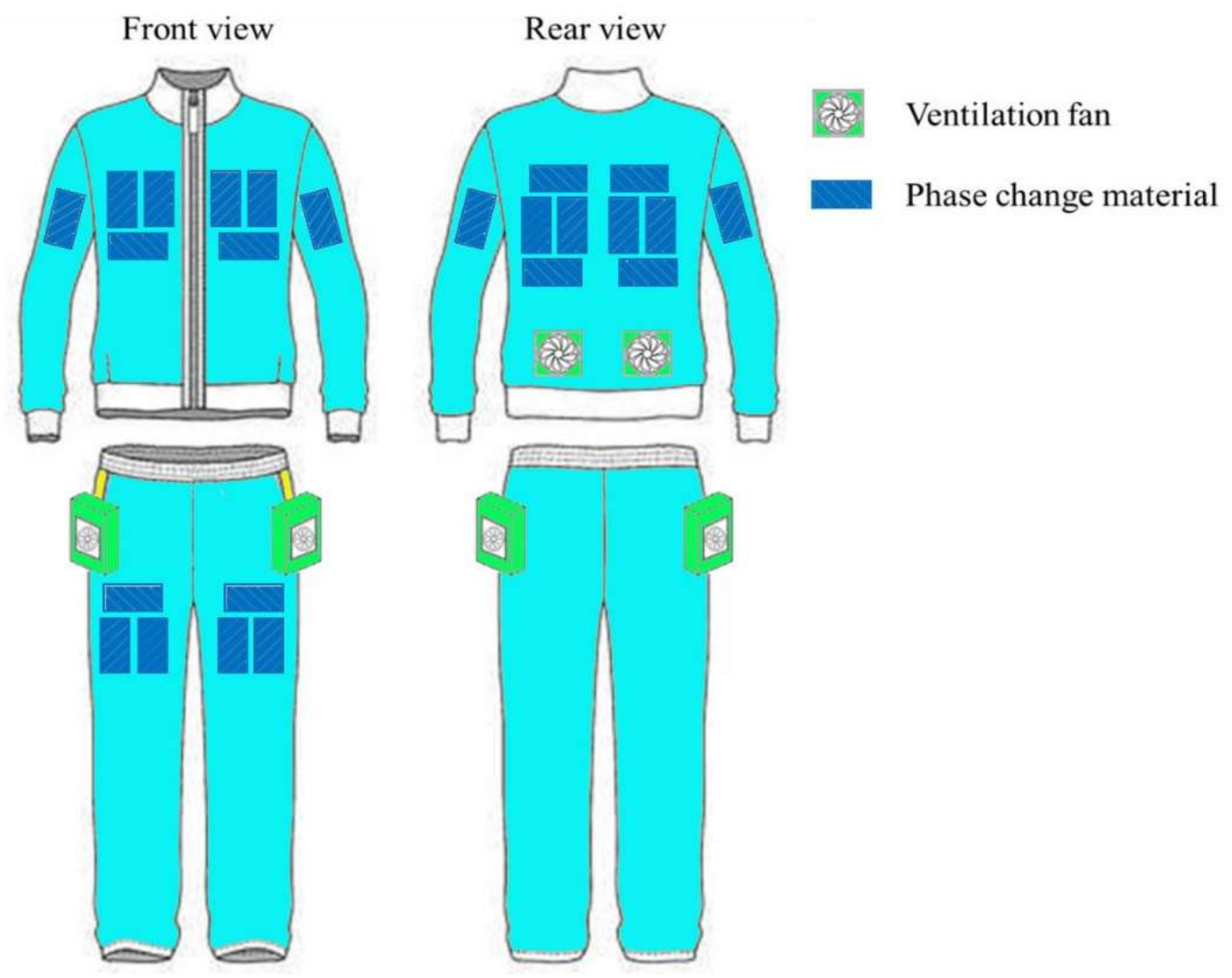

Figure 1. Schematic chart of the new HPCS.

\subsection{Numerical model of the HPCS}

The validated numerical model [26] describing the heat and mass transfer through the new HPCS was applied to investigate the effects of the environment temperature and $\mathrm{RH}$ on the cooling performance of the new HPCS. In this model, the entire body-HPCS system was divided into 5 nude body segments (i.e., head, left foot, right foot, left hand and right hand), 6 clothing-body segments covered with PCMs \& insulation layers (i.e., chest, back, left arm, right arm, left thigh and right thigh), and 11 clothing-body segments without the PCMs \& insulation layers (i.e., chest, back, pelvis, left shoulder, right shoulder, left arm, right arm, left thigh and right thigh, left leg and right leg). Figure 2 shows the configurations of the clothing-body segments without and with PCMs \& insulation layers considered in the numerical study. To simplify the problem, the model was approximated to a onedimensional phenomenon according to the following assumptions [25]:

(1) Local thermal and moisture transports both reach equilibrium instantly in each clothing layer;

(2) The mobile liquid water purely exiting in the underwear layer dispersed into the whole fabric layer throughout the whole segment instantaneously;

(3) The air ventilation by fans is considered as the independent air exchange between the clothing microclimate and the ambient environment for each segment, i.e., no air transport between any adjacent segments;

(4) PCM packs are regarded as a uniform material with a constant thickness, and they closely adhere to the pocket textiles. 


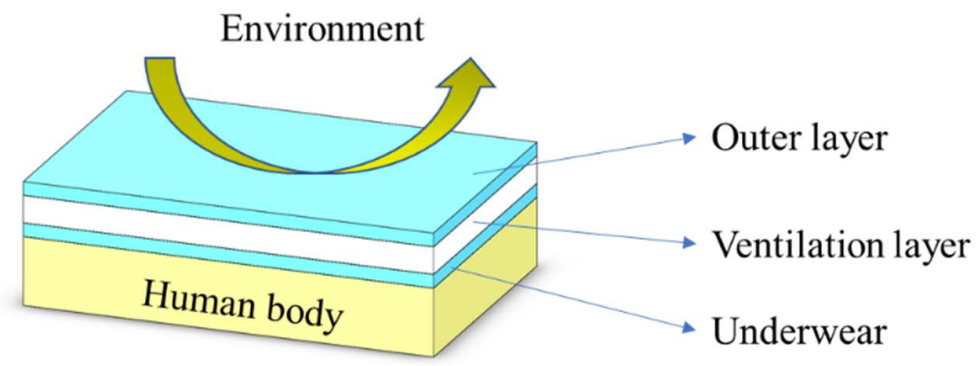

(a)

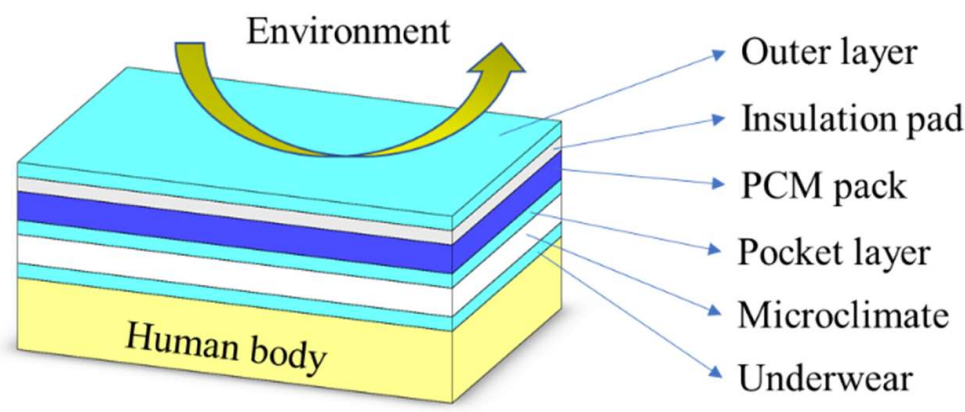

(b)

Figure 2. Configurations of clothing-body segments (a) without and (b) with PCMs \& insulation pads considered for the numerical model.

In this numerical study, the Tanabe's 65-node thermoregulation model [32] and a heat \& moisture transfer clothing model [30] were coupled to solve this problem. It should be noted that the heat and moisture transfer through the human body and the clothing layers are highly coupled together. In the clothing model, the boundary condition of the underwear surface contacting human skin was obtained from the Tanabe's thermoregulation model in each time step.

In the clothing model, heat transfer takes place through all the clothing layers from the underwear layer to the outer clothing layer, whereas the moisture transport only occurs in the fabric layers and the ventilation air layer. The governing equations of the heat and moisture transfer used in the numerical model are given by

$$
\begin{aligned}
& \rho_{k} V_{k} C_{p, k} \frac{d T_{k}}{d t}=q_{c, k-1}-q_{c, k}+q_{l, k}-q_{v, k} \\
& \frac{d M_{k}}{d t}=D_{k-1}-D_{k}+M_{v, k}+M_{s, k}
\end{aligned}
$$

where, $k$ denotes the clothing layer; $t$ is time; $\rho_{k}$ is density; $C_{p, k}$ is specific heat capacity; $V_{k}$ is volume of the discretized clothing layer $k$; $T_{k}$ is temperature; $M_{k}$ is moisture mass; $q_{c, k-1}$ and $q_{c, k}$ are conductive/convective heat flux from layer $k-1$ to layer $k$ and from layer $k$ to layer $k+1$, respectively; $D_{k-1}$ and $D_{k}$ are moisture mass flux by diffusion/convection from layer $k-1$ to layer $k$, and from layer $k$ to layer $k+1$, respectively; $q, k$ is heat released by condensation/absorption of water vapor in fabric layers; $q_{v, k}$ and $M_{v, k}$ are heat and moisture transfer by air ventilation, respectively; $M_{s, k}$ is sweat captured by the innermost layer (i.e., underwear) of the clothing system. In terms of the PCM layers, the apparent heat capacity method[33,34] is applied to solve the heat transfer equation.

\subsection{Simulation parameters}

The numerical simulation investigated scenarios involving 70-min moderate intensity work (metabolic rate: $4.2 \mathrm{METs}$ ) companying with 20-min following rest period (metabolic rate: 1.2 METs). 
The initial PCM temperature was set around $12^{\circ} \mathrm{C}$. A parametric study was carried out to explore the effects of the environmental temperature and $\mathrm{RH}$ on the thermal performance of the new HPCS. The environmental RH was set to $50 \%$ to study the effect of the environmental temperature on the HPCS's cooling performance. Two representative hot environments were chosen to study the effect of the environmental RH on the cooling performance of the new HPCS: a moderately hot environment (i.e., $36^{\circ} \mathrm{C}$ ) and an extremely hot environment (i.e., $40^{\circ} \mathrm{C}$ ). Table 1 gives the variables of the environmental temperature and $\mathrm{RH}$ investigated in the numerical parametric study. The governing equations were discretized by the finite difference method (FDM) in the form of the explicit scheme. The PCM layers, fabric layers and insulation layers include 50, 10 and 6 discrete nodes, respectively. The time step was set to 0.05 second. The simulation code was programmed through MATLAB to couple the Tanabe's thermoregulatory model with the new HPCS clothing model.

Table 1 Environmental temperatures and RHs considered in the parametric study.

\begin{tabular}{ll}
\hline Variables & Values \\
\hline Environmental temperature $\left({ }^{\circ} \mathrm{C}\right)$ & $32,34,36,38,40$ \\
Environmental $\mathrm{RH}$ at $36{ }^{\circ} \mathrm{C}(\%)$ & $30,50,70,90$ \\
Environmental $\mathrm{RH}$ at $40{ }^{\circ} \mathrm{C}(\%)$ & $30,50,70,90$ \\
\hline
\end{tabular}

\section{Results and discussion}

In the following discussion, the chest segment covered with/without PCMs \& insulation pads is chosen as the representative body segment to study the effects of the environmental temperature and $\mathrm{RH}$ on the thermal performance of the new HPCS.

\subsection{Effect of environmental temperatures}

Figure 3 shows the effect of the environmental temperature on the development of the PCM temperature, clothing microclimate $\mathrm{RH}$, heat fluxes absorbed by the PCMs from the environment and the body at the chest segment covered with PCMs \& insulation pads at environmental $\mathrm{RH}=50 \%$. Figure 3(a) indicates that the PCM temperature increases linearly during about the initial 10 min due to the sensible heat absorption of the low-temperature PCMs. Subsequently, the PCMs reach the melting temperature $\left(21^{\circ} \mathrm{C}\right)$ which maintains constant during the melting process. After the PCMs are totally melted, the PCM temperature starts to rise again because of the sensible heat absorption of liquid PCMs from the body and the environment. As the increase in the environmental temperature, the PCM melting time-duration reduces due to the large heat absorption from the environment at higher ambient temperatures [see Figure 3(c)]. It is evident that the environmental temperature has a minor effect on the PCM temperature before the PCMs are totally melted. Figure $3(b)$ indicates that the clothing microclimate RH increases promptly in about the initial $10 \mathrm{~min}$. This is because the moderate intensity work results in a large sweat production and evaporation which overweighs the moisture condensation on the PCM inner surface due to the low temporal microclimate $\mathrm{RH}$. With the further increase in the microclimate $\mathrm{RH}$, the sweat evaporation from the skin tends to be suppressed, whereas the moisture in the microclimate of the HPCS increasingly condenses on the inner surface of the PCMs due to the low PCM temperature and higher microclimate $\mathrm{RH}$. Hence, the microclimate $\mathrm{RH}$ increases gradually in the following phase after about the 10th min. When the equilibrium between the moisture condensation and evaporation is reached on the inner surface of the PCM packs, the moisture in the clothing microclimate could not be further condensed on the PCM surface. In contrast, the sweat on the skin surface still continues evaporating. Consequently, the microclimate $\mathrm{RH}$ will dramatically rise to $100 \%$ after the gradual increase phase. It should be noted that, during the gradual increase phase, the microclimate $\mathrm{RH}$ is larger and soars to $100 \%$ earlier at higher environmental temperatures. This is because the high environmental temperature induces a high saturated vapor pressure in the clothing microclimate and thus the sweat 
evaporation from the skin will be enhanced. Once the microclimate $\mathrm{RH}$ reaches $100 \%$, it will last until the end of the simulation regardless of the environmental temperatures.

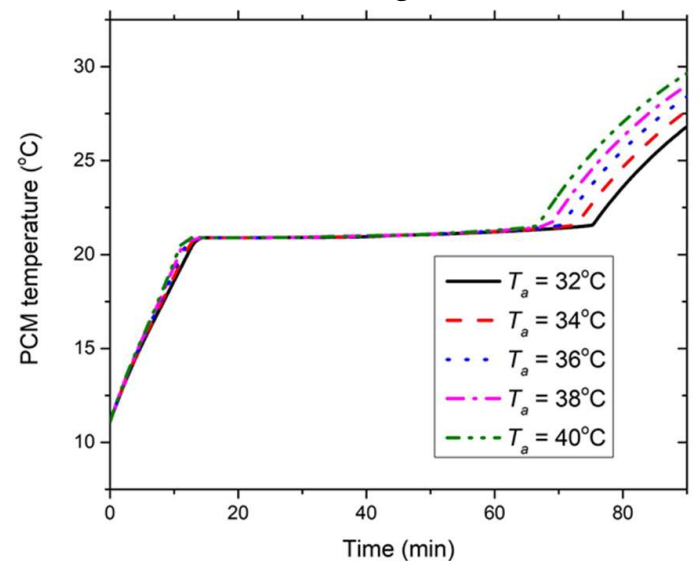

(a)

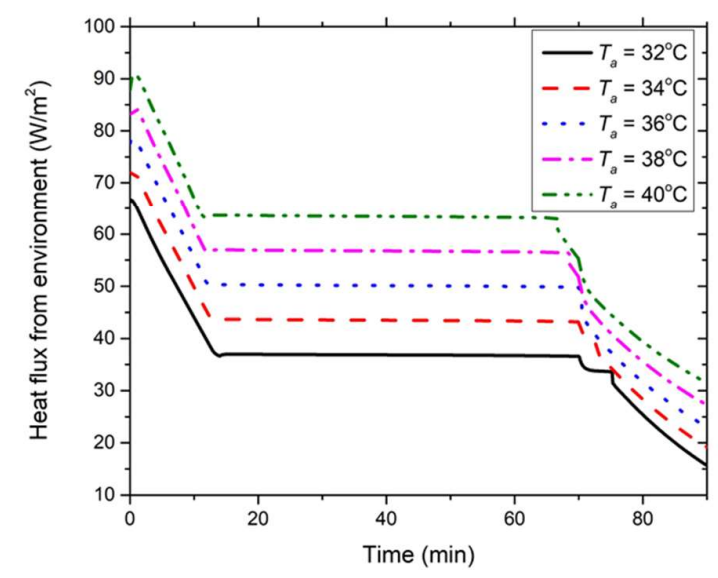

(c)

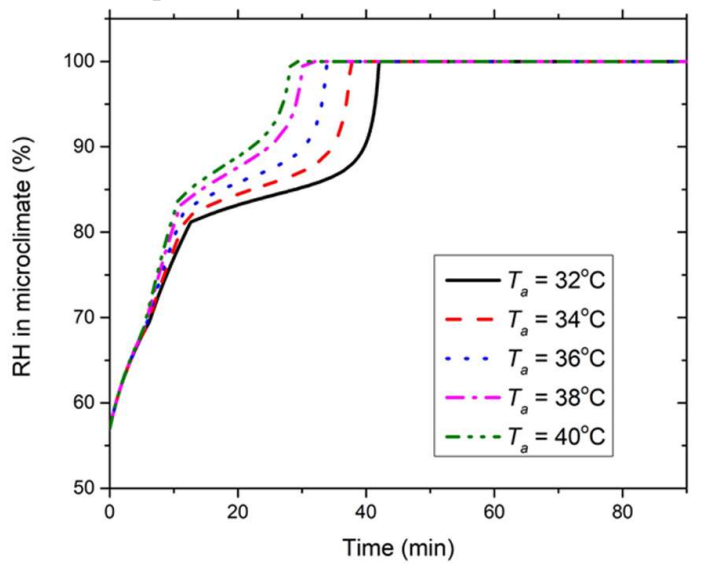

(b)

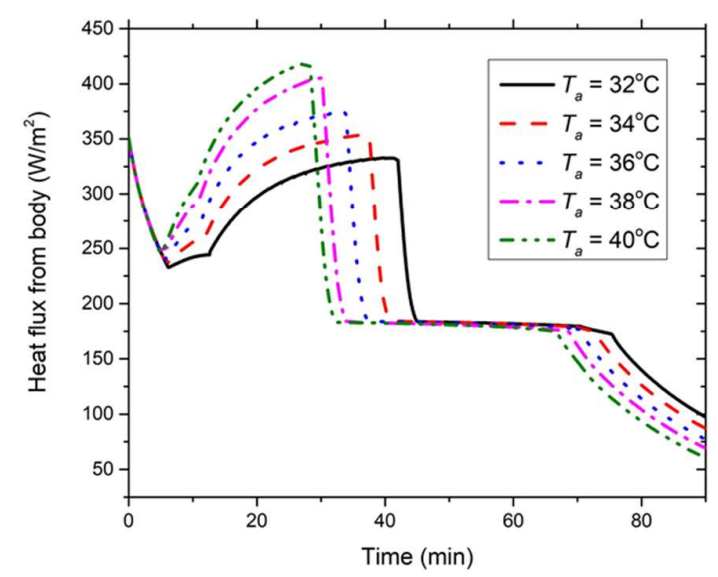

(d)

Figure 3. Effect of environmental temperature on the time course (a) PCM temperature, (b) clothing microclimate $\mathrm{RH}$, (c) PCM heat absorption from the environment and (d) PCM heat absorption from the body at the chest segment covered with PCMs \& insulation pads at environmental $\mathrm{RH}=50 \%$.

Figure 3(c) shows that the heat flux absorbed by the PCMs from the environment decreases till around the 10th min due to the increasing PCM temperature. Afterwards, the heat flux reaches a lower steady level induced by the constant melting temperature of the PCMs. After the PCMs are totally melted, the decrease of the heat flux from environment appears again, which is caused by the corresponding PCM temperature increase as indicated in Figure 3(a). The heat absorption by PCMs from the environment increases with the increase in the environmental temperature because the high environmental temperature leads to a large temperature gradient between the PCMs and the environment. Figure 3(d) denotes that the heat flux absorbed by the PCMs from the body exhibits a significant drop during about the initial $5 \mathrm{~min}$. This is caused by the PCM temperature growth [see Figure 3(a)] as well as the local skin temperature decrease [see Figure 4(a)]. Afterwards, the heat flux increases greatly to the highest value, which is probably induced by the increasing local skin temperature and also by the increasing moisture condensation on the PCM surface due to the growing microclimate RH. During this rapid increasing period (i.e., the 10-30th min), the heat flux drawn from the body increases with the increasing environmental temperature, which is because higher environmental temperatures result in higher microclimate RHs and thereby enhance the moisture condensation heat release on the PCM surface. After the microclimate RH reaches 100\%, the moisture in the clothing microclimate could not be condensed on the PCM surface any longer, leading 
to the absence of the heat released by moisture condensation. As a result, the heat flux from the body steps down from the highest value to a lower level (during the PCM melting process) once the microclimate RH rises to $100 \%$ [see Figs. 3(b) and 3(d)]. After PCMs are totally melted, the heat flux from the body starts to decrease almost linearly because of the temperature increase in the liquid PCMs and, meanwhile, it decreases with the increasing environmental temperature because high environmental temperature corresponds to high PCM temperature [see Figure 3(a)] leading to small temperature gradient between the body and the PCMs.

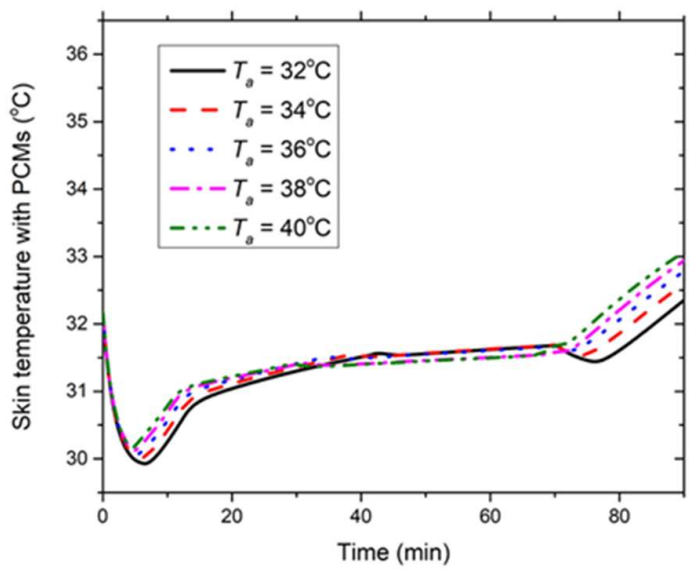

(a)

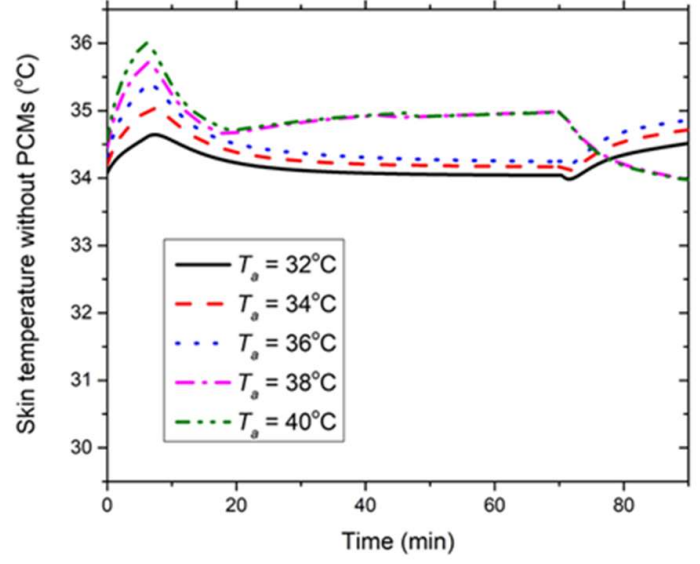

(b)

Figure 4. Effect of environmental temperature on time course chest skin temperatures (a) with and (b) without PCMs \& insulation layers at environmental $\mathrm{RH}=50 \%$.

Figure 4 shows the effect of environmental temperature on the development of the chest skin temperature with and without PCMs \& insulation layers at environmental $\mathrm{RH}=50 \%$. Figure 4 (a) indicates that the local chest skin temperature covered with PCMs \& insulation pads decreases till about the 5th min due to the low initial PCM temperature. Then, the skin temperature increases to a relatively steady period as the PCM temperature increases to the melting temperature. The environmental temperature has a limited effect on the chest temperature covered with PCMs during the 70-min moderate intensity work. After the PCMs are totally melted, the skin temperature starts to rise because the increasing PCM temperature reduces the heat dissipation from the skin. It should be noted that the skin temperature has a slight drop at the 70 th $\min$ at $32{ }^{\circ} \mathrm{C}$, which is because the heat production declines due to the termination of the moderate intensity work but the PCMs are still under the melting process. In contrast, Figure 4(b) shows that the local chest skin temperature without PCMs \& insulation layers increases in about the initial $5 \mathrm{~min}$ because of the large heat production due to the moderate intensity work. Meanwhile, during this period, the high environmental temperature corresponds to the high local skin temperature. Afterwards, the skin temperature decreases to a relatively lower level because the increasing skin temperature induces large sweat generation and thereby intensive evaporative heat dissipation from the skin. When the environmental temperature is $\leq 36{ }^{\circ} \mathrm{C}$, it has a minor effect on the skin temperature and the chest temperature increases after the 70th $\mathrm{min}$. This is because the termination of the moderate intensity work results in low sweat generation leading to smaller evaporative heat dissipation from the skin. However, when the environmental temperature is $\geq 38^{\circ} \mathrm{C}$, the local chest skin temperature is much higher than the aforementioned cases $\left(\leq 36^{\circ} \mathrm{C}\right)$ and it decreases after the 70 th min. At sufficiently high environmental temperatures, the ventilation air could transport much heat to the skin leading to large sweat generation that cannot be completely evaporated. In these cases, the skin is covered with sweat film and the evaporative heat dissipation reaches the maximum value, which yet cannot remove the generated body heat. Consequently, the local skin temperature must increase due to the large heat transfer from ventilation air to the skin. After the termination of the moderate intensity work, the heat generation rate decreases, while the evaporative heat dissipation is still intensive due to the 
existing sweat film. Hence, the skin temperature without PCMs \& insulation layers declines after the 70th min at sufficiently high environmental temperatures (e.g., $\geq 38^{\circ} \mathrm{C}$ ).

Figure 5 shows the effect of the environmental temperature on the development of the core temperature and the mean skin temperature at environmental $\mathrm{RH}=50 \%$. Figure $5(\mathrm{a})$ indicates that the core temperature increases in the first $70 \mathrm{~min}$ due to the large metabolic heat generation during the period of the moderate intensity work. After the 70th min, the core temperature decreases because of the heat production decline caused by the completion of the moderate intensity work. Furthermore, the core temperature increases with the increasing environmental temperature. This is because high environmental temperature reduces the temperature gradient between the body and the environment leading to less heat dissipation from the body to the ambient environment. Meanwhile, when the environmental temperature is larger than the skin temperature (e.g., 38 and $40{ }^{\circ} \mathrm{C}$ ), the ventilation air even could transport heat to the body through convection, which also contributes to high core temperatures. In this situation, severe heat strain and heat-related illnesses could be induced. Figure 5(b) denotes that the mean skin temperature first increases till around the 10th min. This demonstrates the skin temperature increment of all the non-PCM covered segments outweighs the temperature decrement of all the PCM-covered segments during the initial $10 \mathrm{~min}$. Then, the mean skin temperature reaches a steady stage because both the skin temperatures with and without PCMs reach the steady levels as shown in Figure 4. At the 70th min, the mean skin temperature has a slight drop and then starts to increase. The temperature drop is caused by the heat production decrease after the termination of the moderate intensity work. The following temperature increase is induced by the PCM temperature increase in the PCM covered segments and also by the low sweat evaporative heat dissipation in the non-PCM covered segments. Moreover, the mean skin temperature increases with the increasing environmental temperature.

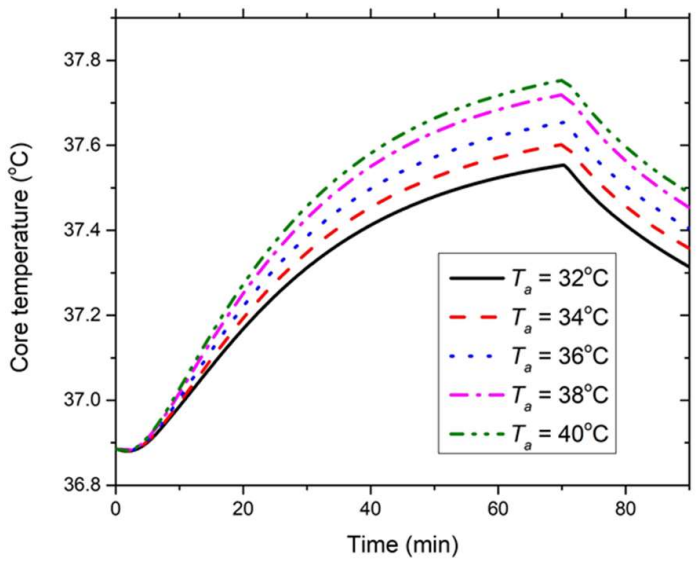

(a)

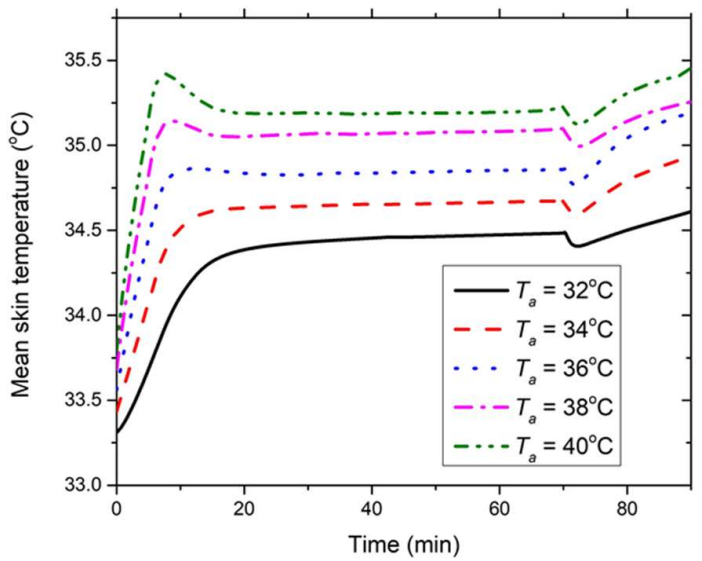

(b)

Figure 5. Effect of environmental temperature on time course (a) core temperature and (b) mean skin temperature at environmental $\mathrm{RH}=50 \%$.

\subsection{Effect of relative humidity in a moderately hot environment $\left(36{ }^{\circ} \mathrm{C}\right)$}

Figure 6 shows the effect of the environmental RH on the development of the PCM temperature, clothing microclimate $\mathrm{RH}$, heat fluxes absorbed by PCMs from the environment and the body at the chest segment covered with PCMs \& insulation pads at $36^{\circ} \mathrm{C}$. Figure $6(\mathrm{a})$ shows the PCM temperature increases from the initial temperature to the melting temperature $\left(21^{\circ} \mathrm{C}\right)$ in about the initial $10 \mathrm{~min}$. Then, the PCM temperature maintains constant during the melting process of the PCMs. After the PCMs are totally melted, the PCM temperature continues to rise due to the sensible heat absorption of liquid PCMs. The environmental RH has little effect on the PCM temperature when the environmental $\mathrm{RH} \leq 70 \%$. In contrast, the melting duration of the PCMs is shortened by about $5 \mathrm{~min}$ at $\mathrm{RH}=90 \%$, which is because too much heat absorption by moisture condensation on the PCM surface at the sufficiently high environmental RH. Hence, the PCM temperature at environmental RH=90\% 
is the highest throughout the 65-90th min. Figure 6(b) describes that the clothing microclimate RH increases rapidly till about the 10th min and then it undergoes a gradual growing phase, after which the microclimate $\mathrm{RH}$ rises dramatically to $100 \%$. The reason is similar to that described in section 3.1 . The environmental RH has a minor effect on the microclimate $\mathrm{RH}$ when the environmental $\mathrm{RH} \leq 70 \%$, whereas the microclimate $\mathrm{RH}$ increases rapidly to $100 \%$ during the gradual increase phase at environmental $\mathrm{RH}=90 \%$. At the sufficiently high environmental $\mathrm{RH}$, the ventilation air contains too much moisture and thus the condensation and evaporation on the PCM surface reach equilibrium at a much earlier time. As a result, the microclimate RH quickly increases to the saturated level at the environmental $\mathrm{RH}=90 \%$.

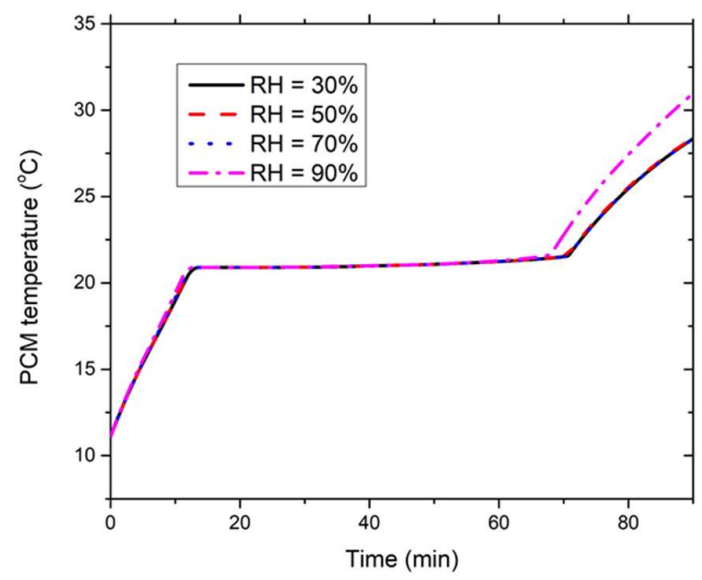

(a)

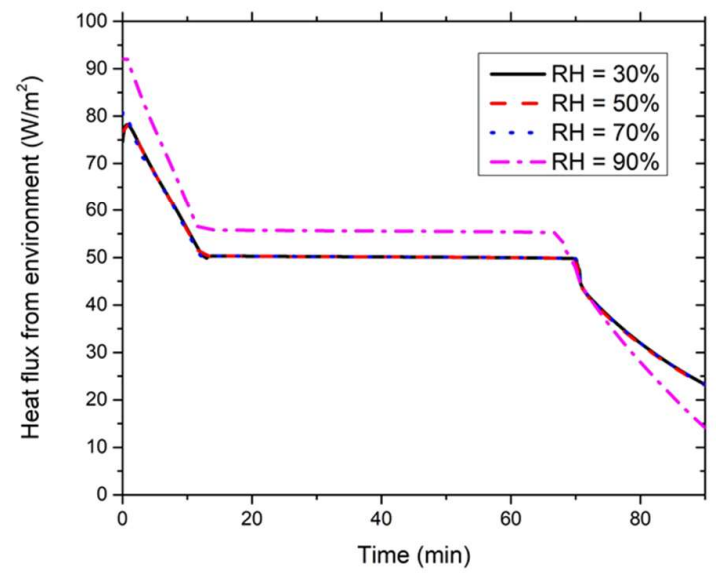

(c)

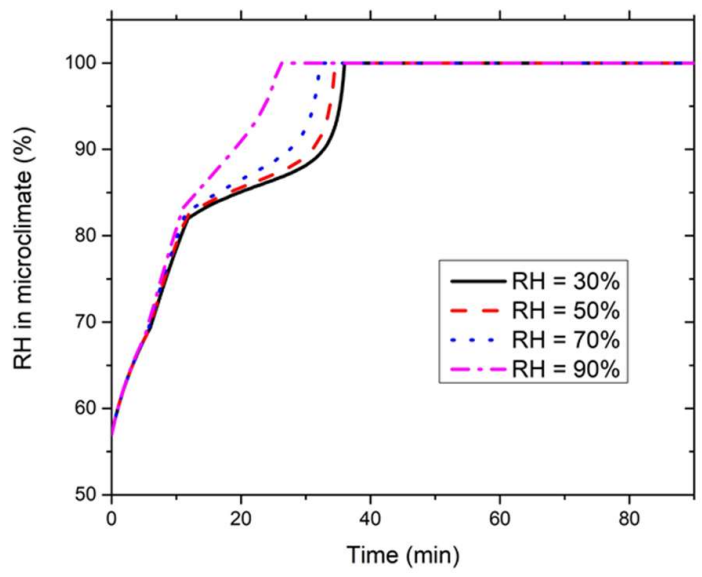

(b)

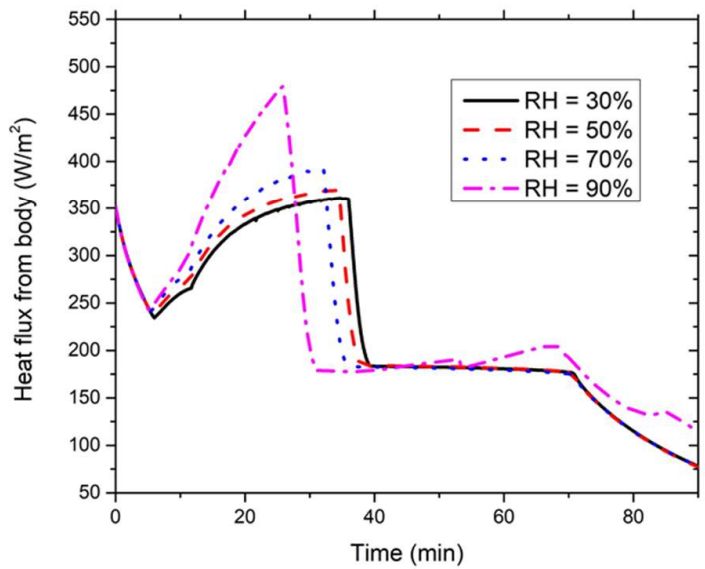

(d)

Figure 6. Effect of environmental RH on time course (a) PCM temperature, (b) clothing microclimate RH, (c) PCM heat absorption from the environment and (d) PCM heat absorption from the body at the chest segment covered with PCMs \& insulation pads at $36{ }^{\circ} \mathrm{C}$.

Figure 6(c) shows that the heat flux absorbed by the PCMs from the environment declines to a lower stable level during about the first $10 \mathrm{~min}$, which corresponds to the initial PCM temperature increment as indicated in Figure 6(a). Afterwards, the stable level maintains during the whole PCM melting process. Once the PCMs are totally melted, the heat flux starts to decrease again because the increasing PCM temperature reduces the temperature gradient between the PCMs and the environment. The environmental RH has little effect on the heat absorption by the PCMs from the hot environment when the environmental $\mathrm{RH} \leq 70 \%$. However, at environmental $\mathrm{RH}=90 \%$, the heat absorption from the environment is larger than the other cases (i.e., $\mathrm{RH} \leq 70 \%$ ) before the PCMs are totally melted, which is caused by more moisture condensation on the outer surface of the PCMs. In 
contrast, after the PCMs are totally melted, the heat flux at environmental $\mathrm{RH}=90 \%$ becomes smaller than those at $\mathrm{RH} \leq 70 \%$, which is induced by the high PCM temperature as indicated in Figure 6(a). Figure 6(d) denotes that the heat flux absorbed by the PCMs from human body decreases till about the 5 th min and then increases to the highest value. Subsequently, the heat flux drops dramatically to a lower stable level, after which it starts to decrease almost linearly. The reason is similar to that demonstrated in section 3.1. The environmental $\mathrm{RH}$ has a limited effect on the heat flux drawn by the PCMs from the body when the environmental $\mathrm{RH} \leq 70 \%$. As for environmental $\mathrm{RH}=90 \%$, the heat flux increases much rapidly from the local lowest point at around 5 th $\min$ to the highest value, because the corresponding high microclimate $\mathrm{RH}$ induces intensive moisture condensation heat release on the PCM surface. It is interesting to note that the heat flux at environmental $\mathrm{RH}=90 \%$ starts to increase at around 45th min during the PCM melting process, which is caused by the increase in the local skin temperature covered with PCMs as shown in the following discussion [see Figure 7(a)].

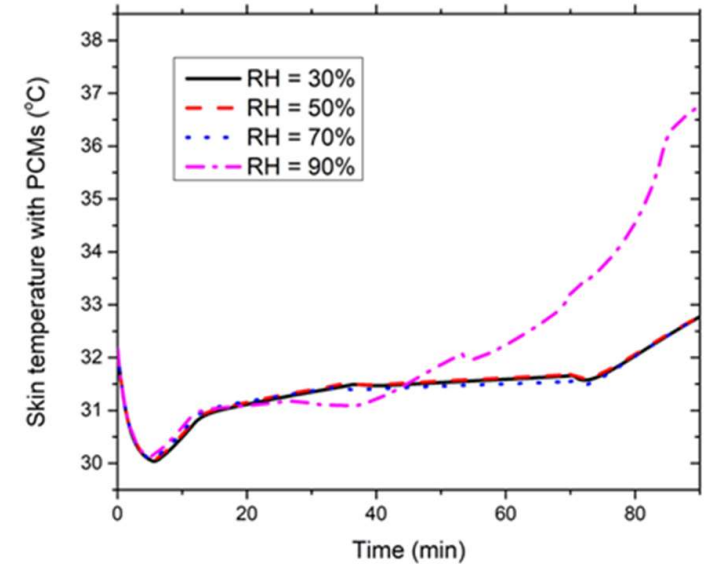

(a)

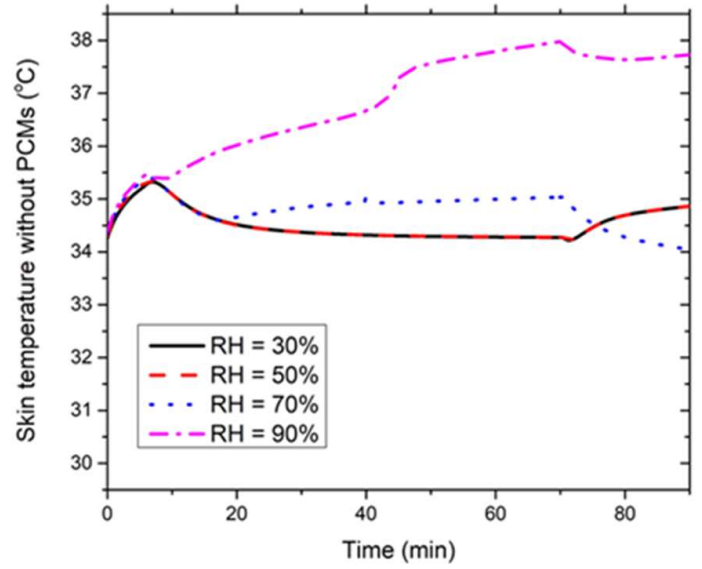

(b)

Figure 7. Effect of environmental RH on time course chest skin temperatures (a) with and (b) without PCMs \& insulation layers at $36^{\circ} \mathrm{C}$.

Figure 7 shows the effect of the environmental $\mathrm{RH}$ on the development of the chest skin temperature with and without PCMs \& insulation layers at $36^{\circ} \mathrm{C}$. Figure $7(\mathrm{a})$ indicates that the local chest skin temperature covered with PCMs first decreases in around the initial 5 min and then increases to a relatively steady level. At environmental $\mathrm{RH} \leq 70 \%$, the skin temperature starts to rise after the PCMs are totally melted and the environmental $\mathrm{RH}$ has little effect on the local chest skin temperature covered with PCMs. In contrast, the skin temperature rise appears at around 45th min during the melting process of the PCMs when the environmental $\mathrm{RH}$ reaches $90 \%$. This is because the sufficiently high environmental $\mathrm{RH}$ significantly suppresses the evaporative heat dissipation from skin, whereas the heat production rate is still intensive during the moderate intensity work. Consequently, the skin temperature starts to increase rapidly during the PCM melting process which corresponds to the heat flux rise at about the 45th min as shown in Figure 6(d). Figure 7(b) shows that the local chest skin temperature without PCMs increases till about the 5th min. Afterwards, the skin temperature decreases to a relatively steady level at environmental $\mathrm{RH} \leq 70 \%$ due to the evaporative heat dissipation from the skin. As for environmental $\mathrm{RH}=90 \%$, the local skin temperature continues increasing rapidly till the 70th $\mathrm{min}$. In this case, the evaporative heat dissipation reaches the maximum value rapidly, which is not yet sufficient to take away the body heat generated by the moderate intensity work. In addition, the skin temperature at environmental $\mathrm{RH}=70 \%$ is larger than that at $\mathrm{RH}=30 \%$ or $50 \%$ during the relatively steady stage. This is because the evaporative heat dissipation at $\mathrm{RH}=70 \%$ has already reached the maximum value at about the 20 th min and thereby the skin temperature has to maintain at a higher level to reduce the convective heat transfer from the ventilation air to the skin. Noticeably, the skin temperature at $\mathrm{RH} \leq 50 \%$ starts to increase from the 70th min because the termination of the moderate intensity work reduces the sweat generation weakening the evaporative heat dissipation. In contrast, the skin temperature at $\mathrm{RH} \geq 70 \%$ decreases 
from the 70th min. This is because the heat production decreases due to the completion of the moderate intensity work, whereas the evaporative heat dissipation is still intensive due to the existing sweat film on the skin.

Figure 8 shows the effect of the environmental $\mathrm{RH}$ on the development of the core temperature and mean skin temperature at $36^{\circ} \mathrm{C}$. Figure $8(\mathrm{a})$ indicates that the environmental $\mathrm{RH}$ has a minor effect on the core temperature when the environmental $\mathrm{RH} \leq 70 \%$. However, the core temperature at environmental $\mathrm{RH}=90 \%$ increases significantly (even higher than $38{ }^{\circ} \mathrm{C}$ ), which is induced by the suppression of the evaporative heat dissipation due to the high moisture content in the ventilation air. Similarly, Figure 8(b) denotes that the environmental RH has a limited effect on the mean skin temperature at environmental $\mathrm{RH} \leq 70 \%$, while the mean skin temperature increases greatly at $\mathrm{RH}=90 \%$. Therefore, the new HPCS is not applicable in the moderately hot environment $\left(36^{\circ} \mathrm{C}\right)$ at ambient $\mathrm{RH}=90 \%$.

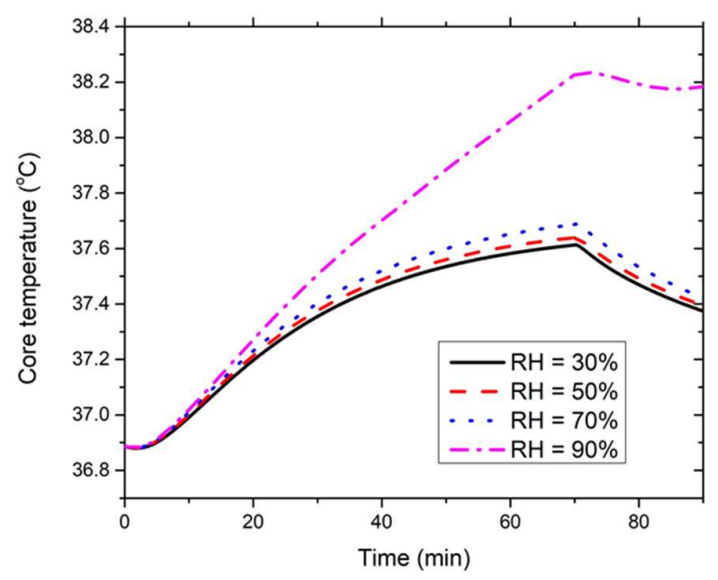

(a)

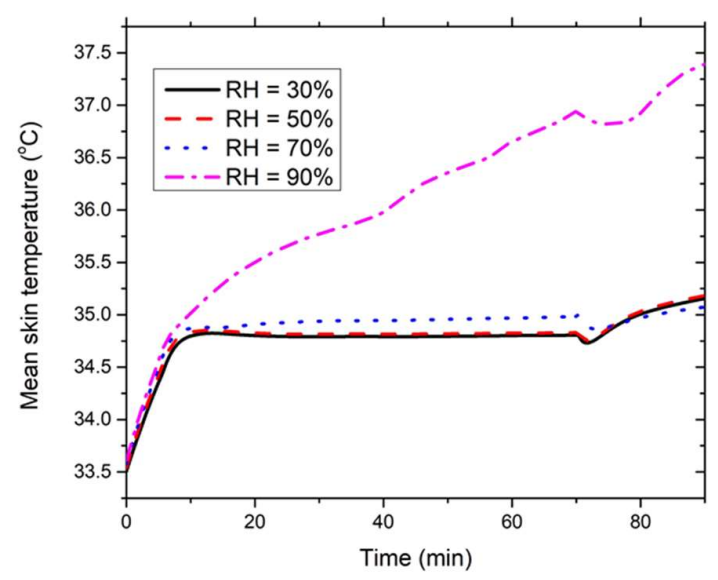

(b)

Figure 8. Effect of environmental $\mathrm{RH}$ on time course (a) core temperature and (b) mean skin temperature at $36^{\circ} \mathrm{C}$.

\subsection{Effect of relative humidity in an extremely hot environment $\left(40{ }^{\circ} \mathrm{C}\right)$}

Figure 9 shows the effect of the environmental RH on the development of the PCM temperature, clothing microclimate $\mathrm{RH}$, heat fluxes absorbed by PCMs from the environment and the body at the chest segment covered with PCMs \& insulation pads at $40{ }^{\circ} \mathrm{C}$. Figure 9(a) indicates that the environmental RH has little effect on the PCM temperature when the environmental $\mathrm{RH} \leq 50 \%$. As for environmental $\mathrm{RH} \geq 70 \%$, the melting period of the PCMs decreases with the increase in the environmental $\mathrm{RH}$ and the higher $\mathrm{RH}$ corresponds to the higher PCM temperature after the PCMs are totally melted. Figure 9(b) denotes that the environmental RH has a minor effect on the clothing microclimate $\mathrm{RH}$ when the environmental $\mathrm{RH} \leq 50 \%$. In contrast, as for environmental $\mathrm{RH} \geq 70 \%$, the microclimate RHs during the gradual increase phase are much larger than those at $\mathrm{RH} \leq 50 \%$, and the microclimate $\mathrm{RH}$ increases with the increasing environmental RH. It should be noted that the microclimate $\mathrm{RH}$ increases rapidly to $100 \%$ without the gradual increase phase at environmental $\mathrm{RH}=90 \%$ because of the high moisture content as well as the intensive sweat generation and evaporation on the skin in the extremely hot environment. 


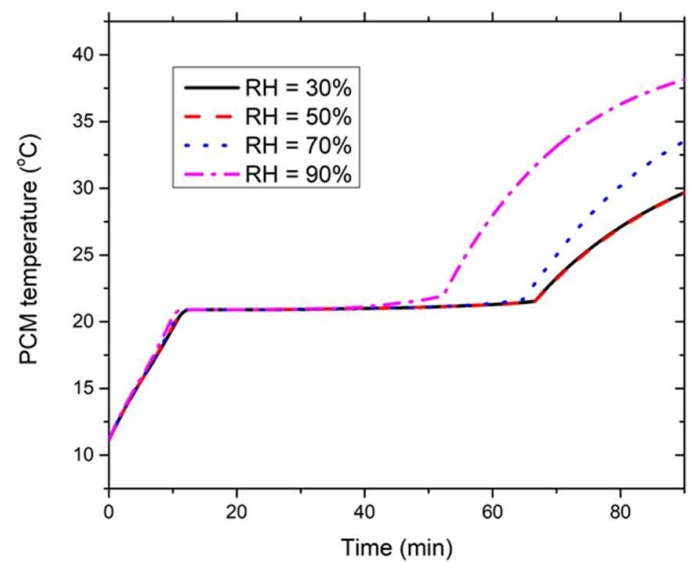

(a)

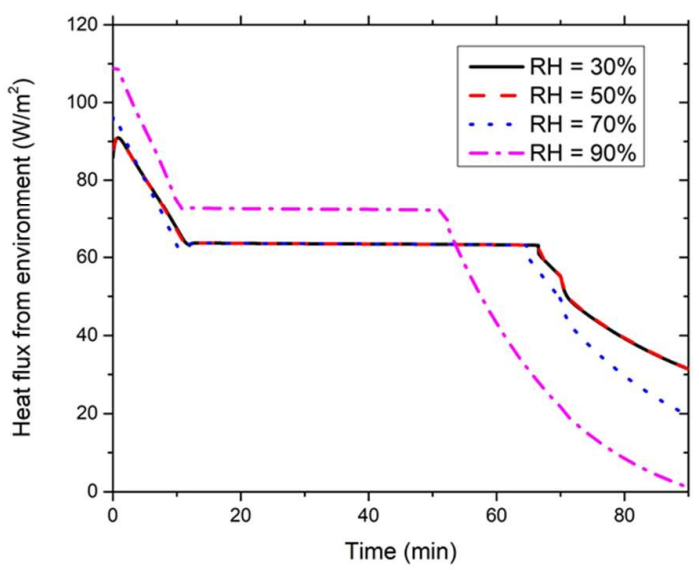

(c)

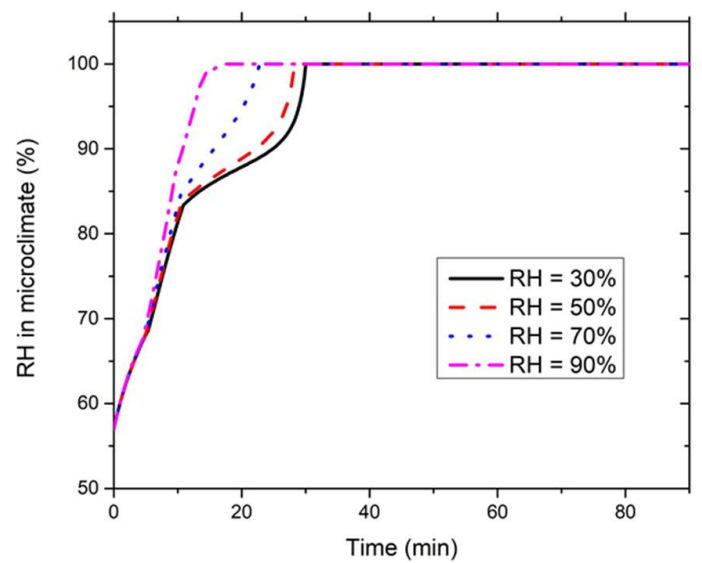

(b)

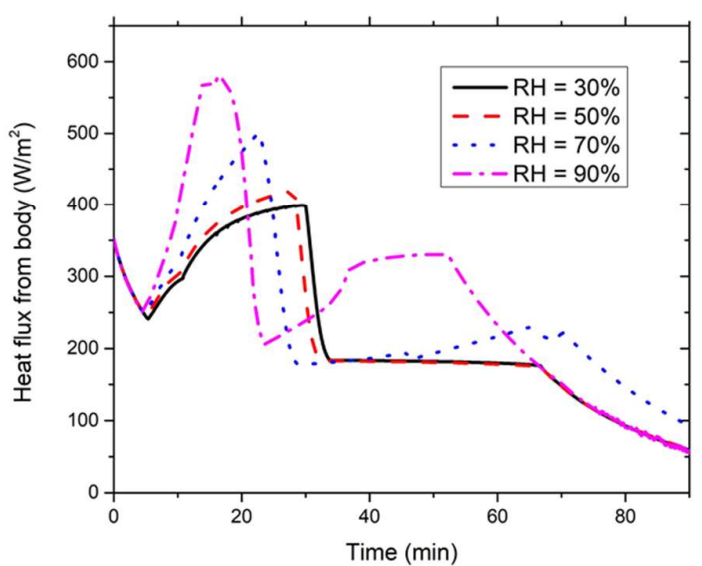

(d)

Figure 9. Effect of environmental $\mathrm{RH}$ on the time course (a) PCM temperature, (b) clothing microclimate RH, (c) PCM heat absorption from the environment and (d) PCM heat absorption from the body at the chest segment covered with PCMs \& insulation pads at $40{ }^{\circ} \mathrm{C}$.

Figure 9(c) shows that the environmental RH has little effect on the heat flux drawn by the PCMs from the environment when the environmental $\mathrm{RH} \leq 50 \%$. In contrast, at environmental $\mathrm{RH}=90 \%$, the heat flux during the initial decreasing phase and the following steady period is higher than the other cases because of the intensive moisture condensation on the outer surface of the PCM packs. Moreover, the heat flux at $\mathrm{RH} \geq 70 \%$ decreases with the increasing environmental $\mathrm{RH}$ after the PCMs are totally melted, which is caused by the high PCM temperature at high environmental $\mathrm{RH}$ as indicated in Figure 9(a). Figure 9(d) shows that the environmental RH has a limited effect on the heat absorption by the PCMs from the body at environmental RH $\leq 50 \%$. However, as for environmental $\mathrm{RH} \geq 70 \%$, the highest value of the heat flux increases significantly with the increase in the environmental RH. This is because the high microclimate RH [see Figure 9(b)] enhances the moisture condensation heat release on the PCM surface. Meanwhile, after the step-down process of the heat flux at microclimate $\mathrm{RH}=100 \%$, the heat flux at environmental $\mathrm{RH} \geq 70 \%$ starts to increase during the PCM melting process and the increasing time point appears earlier at higher environmental RH. This is induced by the increasing local skin temperature covered with PCMs as shown in the following discussion [see Figure 10(a)]. 


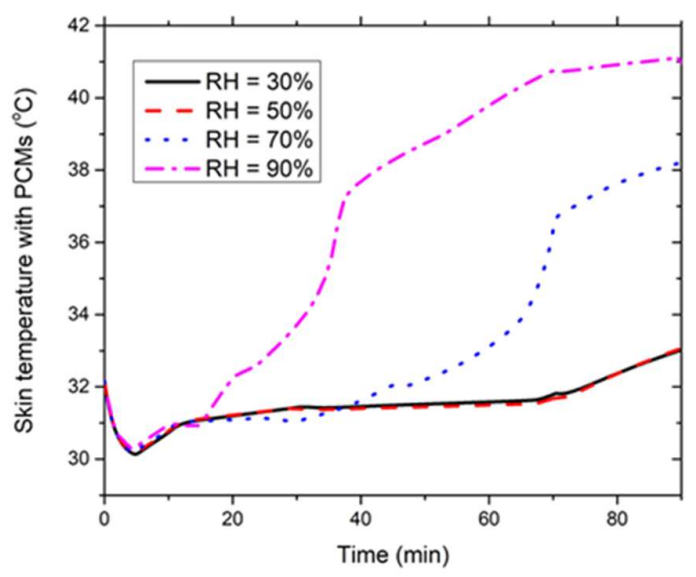

(a)

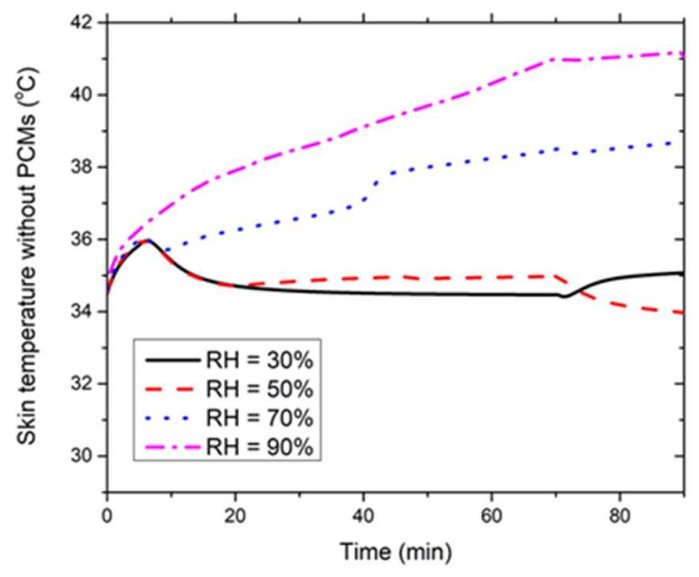

(b)

Figure 10. Effect of environmental RH on time course chest skin temperatures (a) with and (b) without PCMs \& insulation layers at $40^{\circ} \mathrm{C}$.

Figure 10 shows the effect of the environmental $\mathrm{RH}$ on the development of the chest skin temperature with and without PCMs \& insulation layers at $40{ }^{\circ} \mathrm{C}$. Figure $10(\mathrm{a})$ indicates that the environmental RH has little effect on the local chest skin temperature covered with PCMs when the environmental $\mathrm{RH} \leq 50 \%$. In contrast, when the ambient $\mathrm{RH}$ increases to $70 \%$ or higher, heat gain significantly outweighs the heat loss and the chest temperatures increase greatly even during the PCM melting process. The time point at which chest temperature starts to increase appears earlier with the increasing environmental RH. This is mainly because high environmental RH suppresses the evaporative heat dissipation from the skin to the environment, whereas the ventilation air intensively transport heat to the skin due to the extremely high environmental temperature. Further, it can be seen from Figure 10(b) that the local chest skin temperature without PCMs increases continuously throughout the entire 90 -min simulation when the environmental $\mathrm{RH} \geq 70 \%$. It is evident that the new HPCS is no longer able to offer sufficient body cooling under such extreme environmental conditions. Meanwhile, higher environmental RHs result in greater chest temperatures.

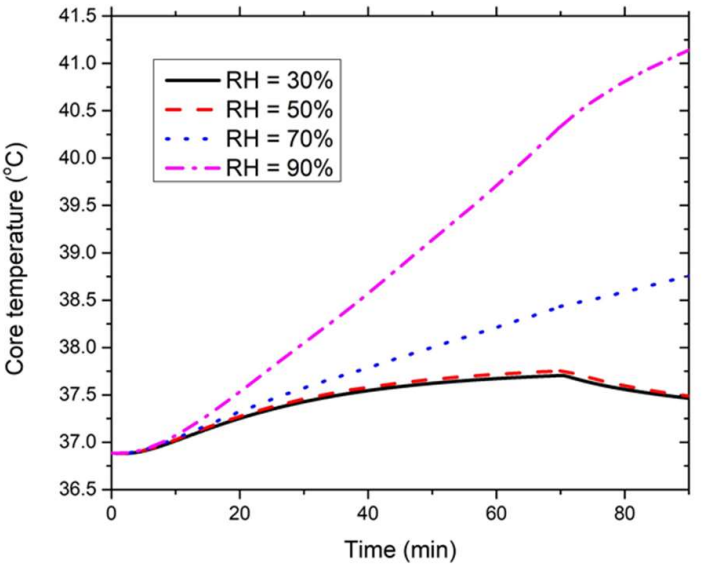

(a)

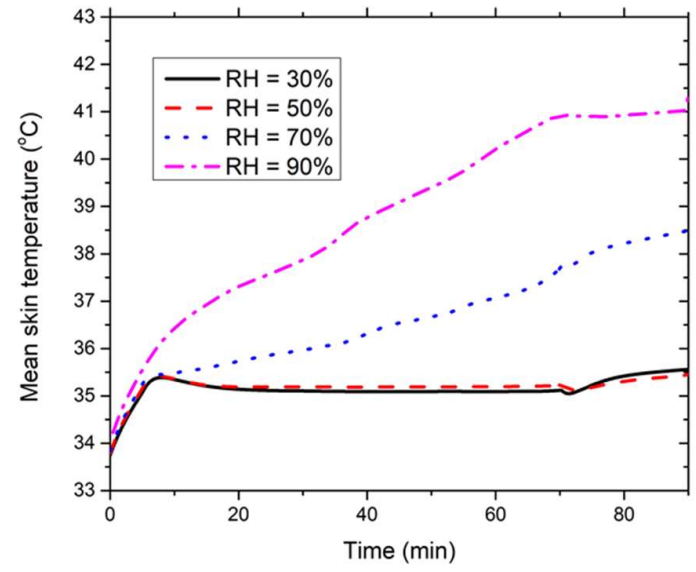

(b)

Figure 11. Effect of environmental $\mathrm{RH}$ on time course (a) core temperature and (b) mean skin temperature at $40^{\circ} \mathrm{C}$.

Figure 11 shows the effect of the environmental $\mathrm{RH}$ on the development of the core temperature and the mean skin temperature at $40{ }^{\circ} \mathrm{C}$. The environmental $\mathrm{RH}$ has a limited effect on the core temperature and mean skin temperature when the environmental $\mathrm{RH} \leq 50 \%$. In contrast, both the core 
temperature and mean skin temperature increase significantly when the environmental $\mathrm{RH} \geq 70 \%$, and the greater environmental RHs correspond to the higher core and mean skin temperatures. This has indicated that the new HPCS could no longer be able provide sufficient body cooling under such extreme environmental conditions. Compared with the results in the moderately hot environment in section 3.2, the effective environmental $\mathrm{RH}$ for the new HPCS with the maximum core temperature at around $37.5{ }^{\circ} \mathrm{C}$ decreases from $70 \%$ to $50 \%$ when the environmental temperature increases from $36{ }^{\circ} \mathrm{C}$ to $40{ }^{\circ} \mathrm{C}$. Therefore, the new HPCS should be improved by adopting EPE pads with high insulation level and PCMs with high latent heat \& low melting temperature based on our previous study[26] so as to make it applicable for the outdoor workers while working in the extremely hot and humid environmental conditions.

\section{Conclusions}

In this study, we carried out a numerical parametric study to investigate the effects of the environmental conditions (i.e., environmental temperature and relative humidity) on the thermal performance of a new HPCS. The results show that both the core temperature and mean skin temperature increase with the growth of the environmental temperature, which means high environmental temperature weakens the thermal performance of the new HPCS. In the moderately hot environment $\left(36^{\circ} \mathrm{C}\right)$, the environmental $\mathrm{RH}$ has a limited effect on the thermal performance of the new HPCS under the environmental $\mathrm{RH} \leq 70 \%$. In contrast, in the extremely hot environment $(40$ ${ }^{\circ} \mathrm{C}$ ), the environmental $\mathrm{RH}$ has a minor effect on the thermal performance of the new HPCS under the environmental $\mathrm{RH} \leq 50 \%$, whereas both the core temperature and the mean skin temperature increase significantly at the environmental $\mathrm{RH} \geq 70 \%$. The environmental $\mathrm{RH}$ for the new HPCS with the maximum core temperature at around $37.5{ }^{\circ} \mathrm{C}$ declines from $70 \%$ to $50 \%$ when the environmental temperature rises from $36^{\circ} \mathrm{C}$ to $40{ }^{\circ} \mathrm{C}$. Therefore, high environmental temperatures and large RHs are harmful to the thermal performance of the new HPCS. Hence, in the working conditions with extremely high environmental temperatures or RHs, the HPCS should be improved by adjusting the PCM properties and the insulation levels to optimize the thermal performance of the new HPCS.

Author Contributions: conceptualization, F.W., U.R. and X.W.; methodology, F.W., U.R. and X.W.; software, X.W. and Z.K.; validation, X.W., Z.K. and F.W.; formal analysis, X.W. and Z.K.; investigation, Z.K.; resources, X.W. and F.W.; data curation, X.W. and F.W.; writing-original draft preparation, Z.K. and F.W.; writingreview and editing, F.W. and B.Y.; visualization, Z.K.; supervision, F.W. and B.Y.; project administration, F.W.; funding acquisition, F.W.

Acknowledgments: This work was financially supported by the General Research Fund of The Hong Kong Polytechnic University (grant codes: 1-ZVLE and G-YBV0).

Conflicts of Interest: The authors declare no conflict of interest.

\section{References}

1. Ratnam, J. V.; Behera, S. K.; Ratna, S. B.; Rajeevan, M.; Yamagata, T., Anatomy of Indian heatwaves. Sci. Rep. 2016, 6, 24395.

2. Klinenberg, E., Heat wave: a social autopsy of disaster in Chicago. University of Chicago Press: Chicago, 2015.

3. Guo, Y.; Gasparrini, A.; Armstrong, B. G.; Tawatsupa, B.; Tobias, A.; Lavigne, E.; Coelho, M.; Pan, X.; Kim, H.; Hashizume, M.; Honda, Y.; Guo, Y. L.; Wu, C. F.; Zanobetti, A.; Schwartz, J. D.; Bell, M. L.; Scortichini, M.; Michelozzi, P.; Punnasiri, K.; Li, S.; Tian, L.; Garcia, S. D. O.; Seposo, X.; Overcenco, A.; Zeka, A.; Goodman, P.; Dang, T. N.; Dung, D. V.; Mayvaneh, F.; Saldiva, P. H. N.; Williams, G.; Tong, S., Heat wave and mortality: a multicountry, multicommunity study. Environ. Health Perspect. 2017, 125, (8), 087006.

4. Hansen, A.; Bi, P.; Nitschke, M.; Ryan, P.; Pisaniello, D.; Tucker, G., The effect of heat waves on mental health in a temperate Australian city. Environ. Health Perspect. 2008, 116, (10), 1369-75.

5. Deng, Q.; Zhao, J.; Liu, W.; Li, Y., Heatstroke at home: prediction by thermoregulation modeling. Build. Environ. 2018, 137, 147-156.

6. Kjellstrom, T.; Holmer, I.; Lemke, B., Workplace heat stress, health and productivity-an increasing challenge for low and middle-income countries during climate change. Glob. Health Action 2009, 2, (1), 2047. 
7. Zhao, M.; Gao, C.; Wang, F.; Kuklane, K.; Holmer, I.; Li, J., A study on local cooling of garments with ventilation fans and openings placed at different torso sites. Int. J. Ind. Ergonom. 2013, 43, (3), 232-237.

8. Guo, T.; Shang, B.; Duan, B.; Luo, X., Design and testing of a liquid cooled garment for hot environments. J. Therm. Biol. 2015, 49-50, 47-54.

9. Bartkowiak, G.; Dabrowska, A.; Marszalek, A., Assessment of an active liquid cooling garment intended for use in a hot environment. Appl. Ergon. 2017, 58, 182-189.

10. Itani, M.; Ghaddar, N.; Ghali, K.; Ouahrani, D.; Chakroun, W., Cooling vest with optimized PCM arrangement targeting torso sensitive areas that trigger comfort when cooled for improving human comfort in hot conditions. Energ. Build. 2017, 139, 417-425.

11. Rothmaier, M.; Weder, M.; Meyer-Heim, A.; Kesselring, J., Design and performance of personal cooling garments based on three-layer laminates. Med. Biol. Eng. Comput. 2008, 46, (8), 825-32.

12. Zhao, D.; Lu, X.; Fan, T.; Wu, Y. S.; Lou, L.; Wang, Q.; Fan, J.; Yang, R., Personal thermal management using portable thermoelectrics for potential building energy saving. Appl. Energy 2018, 218, 282-291.

13. Yang, Y.; Stapleton, J.; Diagne, B. T.; Kenny, G. P.; Lan, C. Q., Man-portable personal cooling garment based on vacuum desiccant cooling. Appl. Therm. Eng. 2012, 47, 18-24.

14. Boriskina, S. V., Nanoporous fabrics could keep you cool. Science 2016, 353, (6303), 986-987.

15. Yazdi, M. M.; Sheikhzadeh, M., Personal cooling garments: a review. J. Text. Inst. 2014, 105, (12), 1231-1250.

16. Al Sayed, C.; Vinches, L.; Hallé, S., Towards Optimizing a Personal Cooling Garment for Hot and Humid Deep Mining Conditions. Open J. Optim. 2016, 05, (01), 35-43.

17. Yazdi, M. M.; Sheikhzadeh, M.; Chavoshi, S. E., Modeling the performance of a PCM cooling vest considering its side effects. Int. J. Cloth. Sci. Tech. 2015, 27, (4), 573-586.

18. Xu, X.; Gonzalez, J., Determination of the cooling capacity for body ventilation system. Eur. J. Appl. Physiol. 2011, 111, (12), 3155-60.

19. Webbon, B.; Montgomery, L.; Miller, L.; Williams, B., A comparison of three liquid-ventilation cooling garments during treadmill exercise. Aviat. Space Environ. Med. 1981, 52, (7), 408-15.

20. Wang, T.; Wang, L.; Bai, L.; Lin, G.; Bu, X.; Liu, X.; Xie, G., Experimental study on the performance of a liquid cooling garment with the application of MEPCMS. Energ. Conv. Manag. 2015, 103, 943-957.

21. Song, W.; Wang, F., The hybrid personal cooling system (PCS) could effectively reduce the heat strain while exercising in a hot and moderate humid environment. Ergonomics 2016, 59, (8), 1009-18.

22. Song, W.; Wang, F.; Wei, F., Hybrid cooling clothing to improve thermal comfort of office workers in a hot indoor environment. Build. Environ. 2016, 100, 92-101.

23. Guo, Y.; Chan, A. P. C.; Wong, F. K. W.; Li, Y.; Sun, S.; Han, X., Developing a hybrid cooling vest for combating heat stress in the construction industry. Text. Res. J. 2017, 004051751774368.

24. Yi, W.; Zhao, Y.; Chan, A. P. C., Evaluating the Effectiveness of Cooling Vest in a Hot and Humid Environment. Ann. Work. Expo. Health 2017, 61, (4), 481-494.

25. Wan, X.; Wang, F.; Udayraj, Numerical analysis of cooling effect of hybrid cooling clothing incorporated with phase change material (PCM) packs and air ventilation fans. Int. J. Heat Mass Transfer 2018, 126, 636648.

26. Kang, Z.; Udayraj; Wan, X.; Wang, F., A new hybrid personal cooling system (HPCS) incorporating insulation pads for thermal comfort management: Experimental validation and parametric study. Build. Environ. 2018, 145, 276-289.

27. Zhao, M.; Gao, C.; Wang, F.; Kuklane, K.; Holmér, I.; Li, J., The torso cooling of vests incorporated with phase change materials: a sweat evaporation perspective. Text. Res. J. 2012, 83, (4), 418-425.

28. Chinevere, T. D.; Cadarette, B. S.; Goodman, D. A.; Ely, B. R.; Cheuvront, S. N.; Sawka, M. N., Efficacy of body ventilation system for reducing strain in warm and hot climates. Eur. J. Appl. Physiol. 2008, 103, (3), 307-14.

29. Du, Y.; Wang, S.; Jin, L. Z.; Wang, S.; Gai, W. M., Experimental investigation and theoretical analysis of the human comfort prediction model in a confined living space. Appl. Therm. Eng. 2018, 141, 61-69.

30. Wan, X.; Fan, J., A transient thermal model of the human body-clothing-environment system. J. Therm. Biol. 2008, 33, (2), 87-97.

31. Gao, C.; Kuklane, K.; Wang, F.; Holmer, I., Personal cooling with phase change materials to improve thermal comfort from a heat wave perspective. Indoor Air 2012, 22, (6), 523-30. 
32. Tanabe, S.; Kobayashi, K.; Nakano, J.; Ozeki, Y.; Konishi, M., Evaluation of thermal comfort using combined multi-node thermoregulation $(65 \mathrm{MN})$ and radiation models and computational fluid dynamics (CFD). Energ. Build. 2002, 34, (6), 637-646.

33. Antony Aroul Raj, V.; Velraj, R., Heat transfer and pressure drop studies on a PCM-heat exchanger module for free cooling applications. Int. J. Therm. Sci. 2011, 50, (8), 1573-1582.

34. del Barrio, E. P.; Dauvergne, J. L., A non-parametric method for estimating enthalpy-temperature functions of shape-stabilized phase change materials. Int. J. Heat Mass Transfer 2011, 54, (5-6), 1268-1277. 